\title{
Evidence for co-invasion events: different chigger species (Actinotrichida, Trombidioidea: trombiculidae) share a host
}

\author{
Hanna Moniuszko $^{1}$ (D) Magdalena Felska ${ }^{1}$ (D) Joanna Mąkol ${ }^{1}$
}

Received: 21 July 2018 / Accepted: 3 September 2018 / Published online: 12 September 2018

(c) The Author(s) 2018

\begin{abstract}
Cases of co-invasion of various chigger species parasitizing murids and cricetids in various habitats were analysed using morphological and molecular approaches. Here we provide evidence for 25 new cases of co-parasitism of chigger mites on rodent hosts (Myodes glareolus, Apodemus flavicollis, Apodemus agrarius) accounting for $8.6 \%$ of all host-parasite associations observed in this study. The results confirm higher incidence of co-parasitism in vertebrate-associated Parasitengona mites compared to arthropod-associated ones. Among factors influencing the occurrence of co-parasitism in Trombiculidae the body constitution and year-round availability of hosts associated with lower host specificity of larvae should be considered.
\end{abstract}

Keywords Co-parasitism $\cdot$ Trombiculidae $\cdot$ Rodents $\cdot$ Host specificity $\cdot$ Topic preferences

\section{Introduction}

Trombiculid larvae, with few exceptions (Felska et al. 2018, and references therein) display host-parasite associations with vertebrates, mainly small mammals, as opposed to other parasitengones, which, except for few species (e.g. Microtrombidium hirsutum Womersley and Johnstoniana rapax Wendt et Eggers) which have departed from a parasitic lifestyle (Wohltmann 2000), encompass arthropod-parasitizing taxa.

The cases of simultaneous parasitism by arthropod-associated parasitengones have been reported by Southcott (1986), Key (1994), Wohltmann (2000, 2001) and Stahr (2014). Wohltmann (2001) estimated the occurrence of different ectoparasitic species on the same host at ca. 3\% of observed invasions involving Parasitengona mites. Such invasions are often accompanied by distinct site preferences displayed by co-occurring species, for example, the water mites Feltria rominji Besseling and Atractides nodipalpis (Thor) parasitizing a chironomid fly, Tanytarsus flavidulus, or the terrestrial Johnstoniana eximia (Berlese) (=J. tuberculata Schweizer) and Calyptostoma velutinum (Müller) parasitizing a limoniid fly, Limonia phragmitidis (Efford 1963; Wohltmann 2001). According to Wohltmann

Joanna Mąkol

joanna.makol@upwr.edu.pl

1 Department of Invertebrate Systematics and Ecology, Institute of Biology, Wrocław University of Environmental and Life Sciences, Kożuchowska 5b, 51-631 Wrocław, Poland 
(2000) the rarity of the phenomenon should be attributed to the fact that species inhabiting the same location generally use different host resources or display a temporal shift in using the same host resources.

Compared to arthropod-associated taxa, vertebrate-associated parasitengones (Trombiculidae s.1.) are thought to display lower selectivity toward hosts in favour of habitat selectivity (Daniel 1961; Goff 1979; Shatrov and Kudryashova 2008). The latter makes the co-occurrence of species more likely due to probably lower competitive interactions on the same host. Cases of co-parasitism of trombiculid species, widely scattered in the literature, refer mostly to the presence of 2-5 species on the same host (Mohr 1956; Daniel 1961; Vercammen-Grandjean 1963, 1975; Goff 1979; Haitlinger 1979; Kharadov and Chirov 2007; Barnard et al. 2015). Despite the close insight of some researchers into the frequency of records, the extent of the phenomenon and its ecological background remain largely unknown.

Here we present the cases of trombiculid co-invasions, discovered during our recent studies, along with the general characteristics of topic preferences displayed by larvae within the hosts' body. In order to confirm the separate identity of co-occurring species, we refer to morphological and molecular evidence.

\section{Materials and methods}

Ectoparasitic larvae were collected from murid [Apodemus agrarius (Pallas), Apodemus flavicollis (Melchior), Apodemus sylvaticus L.] and cricetid [Myodes glareolus (Schreber) and Microtus oeconomus (Pallas)] hosts. The hosts were captured in Sherman traps (permissions no. 66/2012, 27/2013 and 41/2013 issued by the Second Local Commission for Animal Experiments) at 23 localities in Poland, in anthropogenic [A] and natural [N] habitats, from 2012 to 2017 :

(1) Pyrzycko-Stargardzka Plain: Małkocin [A], N5324' E1501', leg. Hanna Moniuszko (HM);

(2) Dolna Narew Valley: Kaszewiec [N], N52 $52^{\prime}$ E $21^{\circ} 26^{\prime}$, leg. HM;

(3) Bielska Plain: Białowieża [N], N52 $41^{\prime}$ E $23^{\circ} 52^{\prime}$, leg. HM;

(4) Wielkopolskie Lake District: Murowana Goślina [A], N52³3' E17º6' leg. HM, Paula Zajkowska (PZ);

(5) Kujawskie Lake District: Babiak [N], N52 $03^{\prime}$ E1 $8^{\circ} 23^{\prime}$, leg. HM;

(6) Twardogórskie Hills: Antonin [A], N51 ${ }^{\circ} 33^{\prime} \mathrm{E} 17^{\circ} 30^{\prime}$, leg. HM;

(7) Milicka Basin: Ruda Milicka [N], N51³1' E1 $8^{\circ} 20^{\prime}$, leg. Joanna Mąkol (JM), Grzegorz Zaleśny (GZ);

(8) Milicka Basin: Milicz [N], N51³0' E17¹5', leg. GZ;

(9) Twardogórskie Hills: Syców [N], N51 ${ }^{\circ} 17^{\prime}$ E $17^{\circ} 42^{\prime}$, leg. HM;

(10) Wieluńska Upland: Szachownica cave [N], N51 $03^{\prime}$ E $18^{\circ} 48^{\prime}$, leg. HM, PZ;

(11) Ślęża Massif: Sobótka [N], N50 $54^{\prime}$ E16 ${ }^{\circ} 44^{\prime}$, leg. HM;

(12) Karkonosze Mts: Szklarska Poręba [N], N5050' E15³5', leg. HM, JM;

(13) Jeleniogórska Basin: Karpacz [N], N5046' E1544', leg. HM;

(14) Częstochowska Upland: Dobrogoszczyce [N], N50³6' E19³3', leg. HM;

(15) Częstochowska Upland: Morsko [A], N50³1' E19²9', leg. HM, JM, PZ;

(16) Stołowe Mts: Ostra Góra [N], N50²9' E16²18', leg. JM, GZ;

(17) Orlickie Mts: Niemojów [N], N5009' E16³3', leg. HM, JM; 
(18) Katowicka Upland: Łaziska [A], N5008' E18 50', leg. HM;

(19) Sanocko-Turczańskie Mts: Olchowiec [N], N4926' E22 $31^{\prime}$, leg. PZ;

(20) Western Tatra Mts: Zakopane [N], N49 $16^{\prime}$ E20 $05^{\circ}$, leg. Jan Cichocki (JC);

(21) Western Bieszczady Mts: Lutowiska [N], N49 $15^{\prime}$ E22 $41^{\prime}$, leg. HM;

(22) Western Tatra Mts: at Zielony Staw [N], N49 $14^{\prime}$ E $19^{\circ} 59^{\prime}$, leg. JC;

(23) Western Bieszczady Mts: Stuposiany [N], N49 $11^{\prime}$ E $22^{\circ} 41^{\prime}$, leg. HM.

Data on collection time (month) are provided in Table 1. Various habitats-including primeval forest, mountain river banks, deciduous mountain forest, mixed forest in a municipal park, ruderal surroundings of an artificial water reservoir and mountain clearing-were represented among the collection sites. Sampling at regular, 2- to 4-week intervals was carried out from September 2012 to September 2014 at locality no. 9, whereas for the remaining localities incidental collecting was applied.

Larvae were preserved in $96 \%$ ethanol. Specimens intended for experimental rearing were transferred to rearing vials, filled to $1 / 3$ with a mixture of plaster-of-Paris and charcoal. The vials were placed in a climatic chamber with $80 \%$ humidity, L12/D12 photoperiod and $22{ }^{\circ} \mathrm{C}$ in light period $/ 15{ }^{\circ} \mathrm{C}$ in the dark, set to imitate those recorded in the natural environment in the period when larvae develop into further instars. The experimental rearing aimed at obtaining subsequent instars from field-collected specimens, aiding also in species identification. The latter is especially important in case of taxa whose knowledge is limited to larvae, as it enables further comparisons with species known also from active post-larval forms, whereas in case of loss or damage of larval exuvia, it constitutes the basis for identification. The morphological description of instars, being beyond the scope of the present paper, will be dealt with separately.

In order to confirm the separate status of species distinguished based on morphological traits, the genetic distance between COI sequences of Neotrombicula inopinata (Oudemans), Miyatrombicula muris (Oudemans) sp. A and sp. B was estimated. The DNA was extracted from four specimens (larvae representing $N$. inopinata and M. muris and adults of tentatively representing spp. A and B). For DNA extraction and isolation protocol see Moniuszko et al. (2015). Amplification of the DNA barcode region (COI) was done using degenerate primers bcdF01 (5'-CATTTTCHACTAAYCATAARGAT ATTGG-3') and bcdR04 (5'-TATAAACYTCDGGATGNCCAAAAAA-3') (Dabert et al. 2010). Multiple alignment was done using the CLUSTALW algorithm, implemented in the MEGA7 package (Kumar et al. 2016), with the default parameters (gap opening penalty-15, gap extension penalty-6.66, both for pairwise and multiple alignment). Pairwise sequence alignment and cutting resulted in a compact 518 bp data block. Distance calculation between sequences was performed using Kimura's two parameter model (K2P) (Kimura 1980) implemented in MEGA7. The sequences of $N$. inopinata and M. muris were deposited in the GenBank under accession numbers MH607466 and MH622154. For the purpose of comparison, we used sequences of Hirsutiella zachvatkini (Schluger) (acc. no. KR071845) and Neotrombicula vulgaris (Schluger) (acc. no. KY888693), earlier deposited in the GenBank (Moniuszko et al. 2015, 2017).

Specimens which served for morphological identification, including also the exoskeletons remaining after DNA extraction, were mounted on microscopic slides in Hoyer's medium. Photos were taken under Nikon Eclipse E600 coupled with DS-Fi1 camera and Nikon Eclipse 80i coupled with DS-Fi3 systems. The morphological identification of species based on larvae was based on the criteria provided by Kudryashova (1998). 


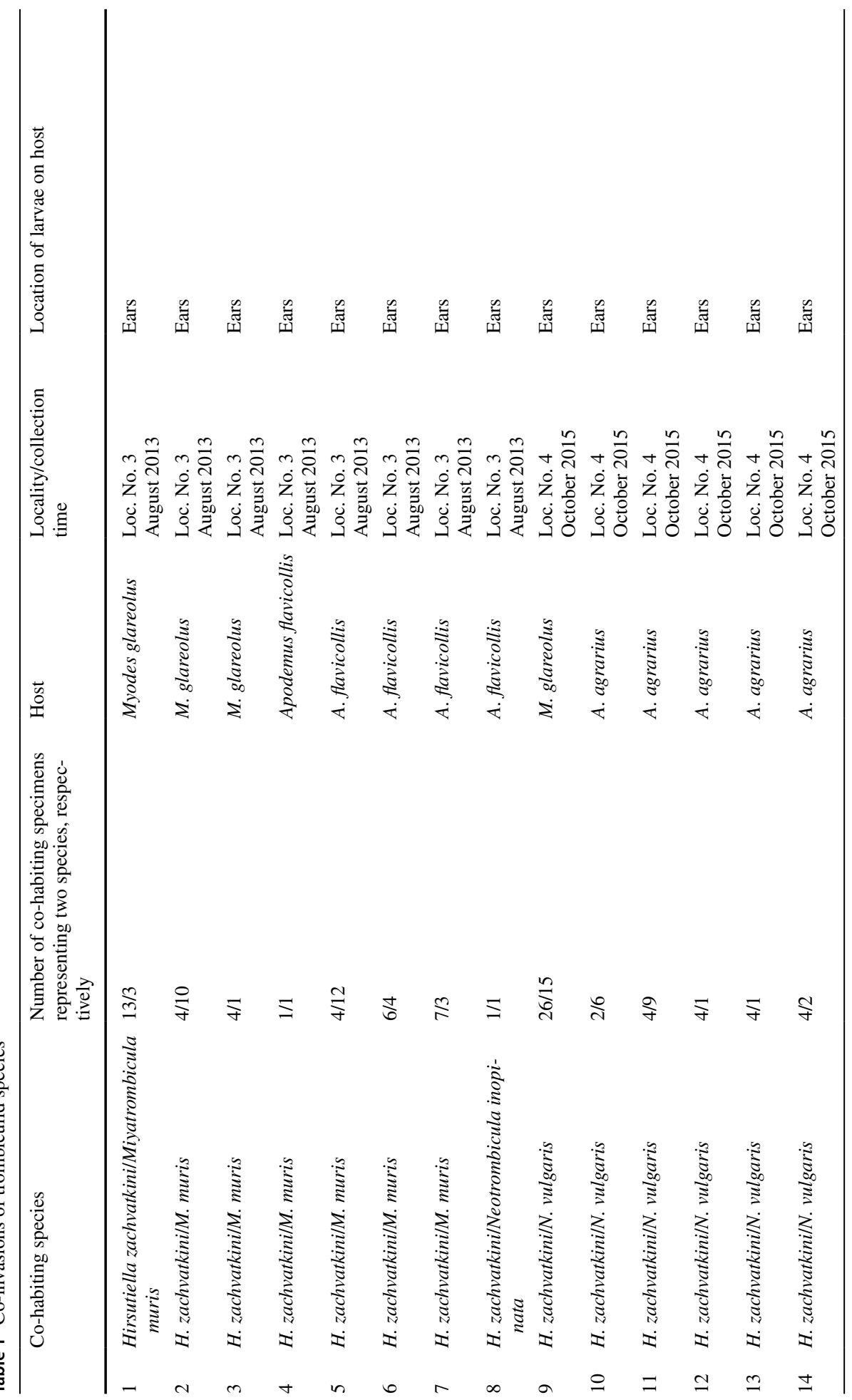




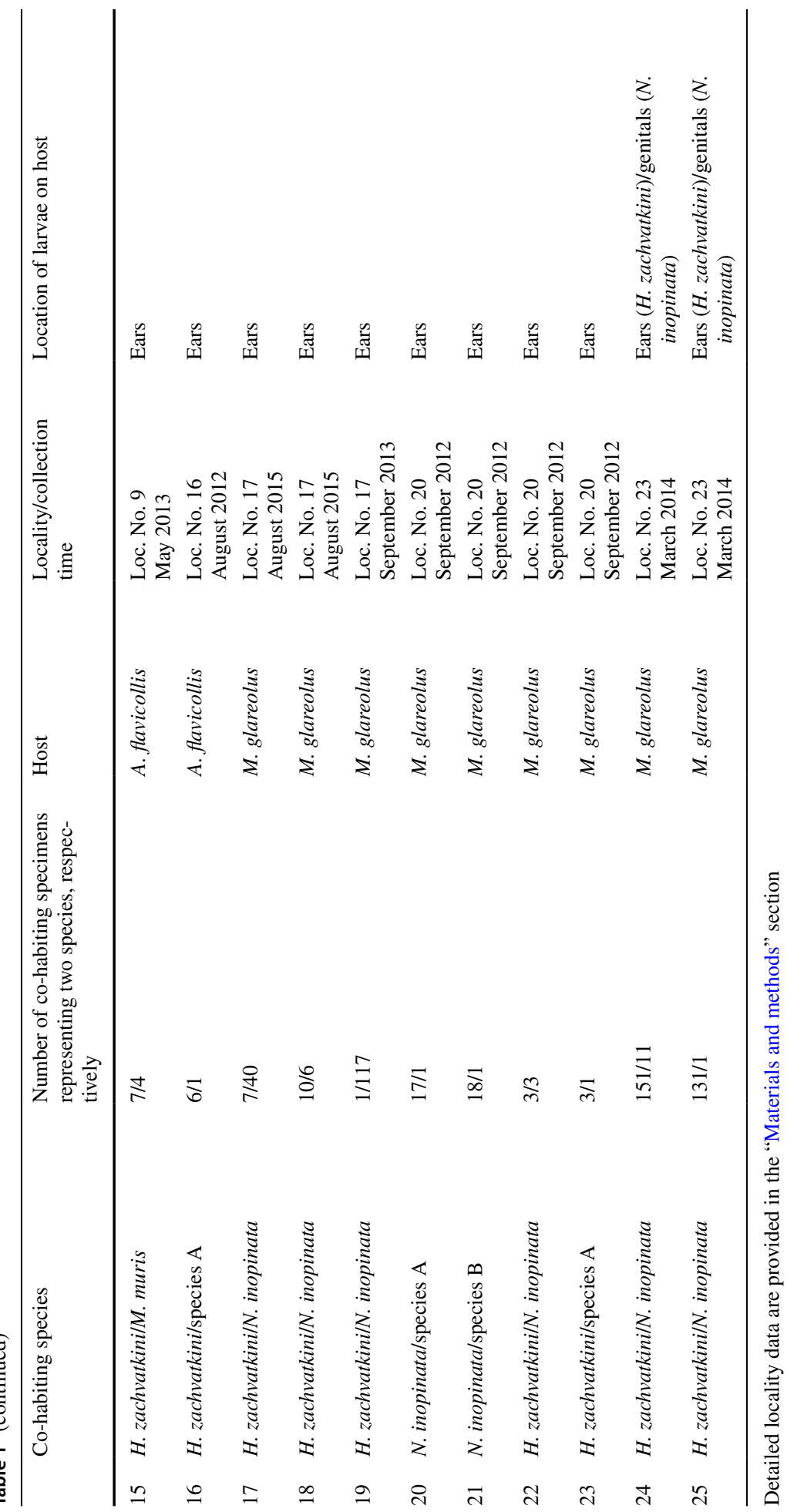




\section{Results}

Of 291 rodents collected in the course of our studies and infested with Trombiculidae, 25 specimens $(8.6 \%)$ carried more than one trombiculid species. Co-parasitizing chigger species (Table 1) were found in three out of five host species, at seven out of 23 localities examined. The hosts with co-occurring chigger species were captured in both disturbed and undisturbed habitats.

Altogether, six pairwise combinations of various sets of species were recorded. Cooccurring mites were assigned to four nominal species: H. zachvatkini, Neotrombicula inopinata, Neotrombicula vulgaris and Miyatrombicula muris. Of those, only M. muris remains known exclusively from larvae. In the course of laboratory rearing we obtained also deutonymphs and adults representing two distinct species, here referred to as sp. A and sp. B, due to the loss of larval exuvia that would allow comparison followed by correlation of instars for species hitherto known exclusively from larvae or would serve for new taxa description. Conspecificity of spp. A and B with H. zachvatkini, N. inopinata and $N$. vulgaris was excluded based on morphological and molecular evidence (for habitus of spp. A and B, H. zachvatkini and N. inopinata see Fig. 1), whereas the value of genetic distance between sp. A, sp. B (forward and reverse strand) and M. muris (reverse strand only) served as evidence for separate status of the latter three taxa. The genetic distance (K2P) between sequences obtained from species involved in multiple infestations ranged from 21.1 to $41.3 \%$. The distance between congeneric species $N$. inopinata
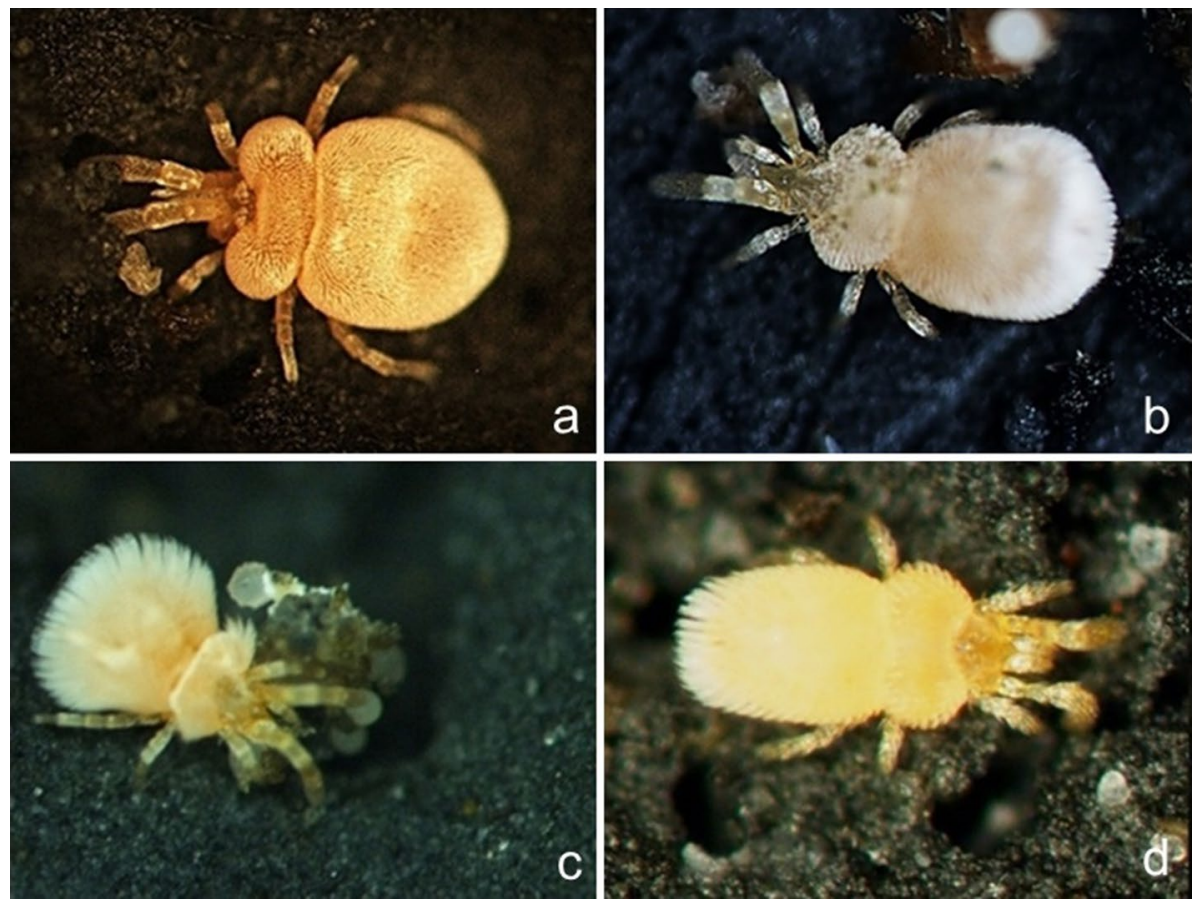

Fig. 1 Active postlarval forms experimentally reared from co-parasitizing larvae: a species A (adult), b species B (adult), c Hirsutiella zachvatkini (adult), d Neotrombicula inopinata (deutonymph) (not to scale) 
and $N$. vulgaris was $24.2 \%$. The most remote sequence from the others $(34.3-41.3 \%)$ was sp. A. The pairwise differences are specified in Table 2.

The distinct specific affiliation of larvae of $H$. zachvatkini, M. muris, $N$. inopinata and $N$. vulgaris was confirmed based on slide-mounted specimens (for structure and chaetotaxy of prodorsal sclerite, being among the main diagnostic traits see Fig. 2), whereas the differences between Neotrombicula spp. and engorged specimens of $H$. zachvatkini could be also preliminarily inferred from the different coloration of idiosoma of live specimens (larvae dark orange in N. inopinata and in N. vulgaris, pale yellow in engorged H. zachvatkini).

The proportion of specimens representing different chigger species co-occurring on one host varied widely - from equal (1:1 on A. flavicollis) to vast predominance of one species (e.g., 131:1 on M. glareolus). The chiggers tended to form clusters, irrespective of the host and parasite species. For the majority of cases (23 out of 25) the larvae were attached to the ears of rodents, whereas only in two cases the parasitism within the genital area was stated. Both cases, however, refer to pairwise association that was recorded also within another part of the body (ears) in other host specimens and/or species, and in both of them the spatial segregation of parasitic larvae was observed.

\section{Discussion}

Cases of co-invasions were recorded in our study in various habitats and on three out of the five host species examined, which confirms the fairly widespread phenomenon. The varying number of samples collected both in anthropogenic and in undisturbed habitats as well as the season-dependent abundance of larvae do not allow to regard the absence of larvae on A. sylvaticus and on M. oeconomus as reflecting host- or habitat-dependent trends in the occurrence of multi-species invasions. The frequency of co-invasions, however, is likely to be higher in habitats influenced by anthropopressure. In his research carried out in Papua

Table 2 Pairwise genetic distance calculation (K2P) [\%] for co-parasitizing trombiculid species

\begin{tabular}{|c|c|c|c|c|c|c|}
\hline & $\begin{array}{l}\text { Species A } \\
\text { [DISE152] }\end{array}$ & $\begin{array}{l}\text { Species B } \\
\text { [DISE153] }\end{array}$ & $\begin{array}{l}\text { Neotrom- } \\
\text { bicula } \\
\text { inopinata } \\
\text { [MH607466] }\end{array}$ & $\begin{array}{l}\text { Miyatrom- } \\
\text { bicula muris } \\
{[\mathrm{MH} 622154]}\end{array}$ & $\begin{array}{l}\text { Hirsutiella } \\
\text { zachvatkini } \\
\text { [KR071845] }\end{array}$ & $\begin{array}{l}\text { N. vulgaris } \\
\text { [KY888693] }\end{array}$ \\
\hline \multicolumn{7}{|l|}{$\begin{array}{l}\text { Species A } \\
\text { [DISE152] }\end{array}$} \\
\hline $\begin{array}{l}\text { Species B } \\
\text { [DISE153] }\end{array}$ & 36.7 & & & & & \\
\hline $\begin{array}{l}\text { Neotrombicula } \\
\text { inopinata } \\
{[\mathrm{MH} 607466]}\end{array}$ & 40.6 & 22.9 & & & & \\
\hline $\begin{array}{l}\text { Miyatrombicula muris } \\
\text { [MH622154] }\end{array}$ & 34.3 & 28.7 & 24.8 & & & \\
\hline $\begin{array}{l}\text { Hirsutiella zachvat- } \\
\quad \text { kini } \\
\text { [KR071845] }\end{array}$ & 41.3 & 27.4 & 21.1 & 23.7 & & \\
\hline $\begin{array}{l}\text { N. vulgaris } \\
\text { [KY888693] }\end{array}$ & 41 & 22.4 & 24.1 & 26.8 & 26.4 & \\
\hline
\end{tabular}




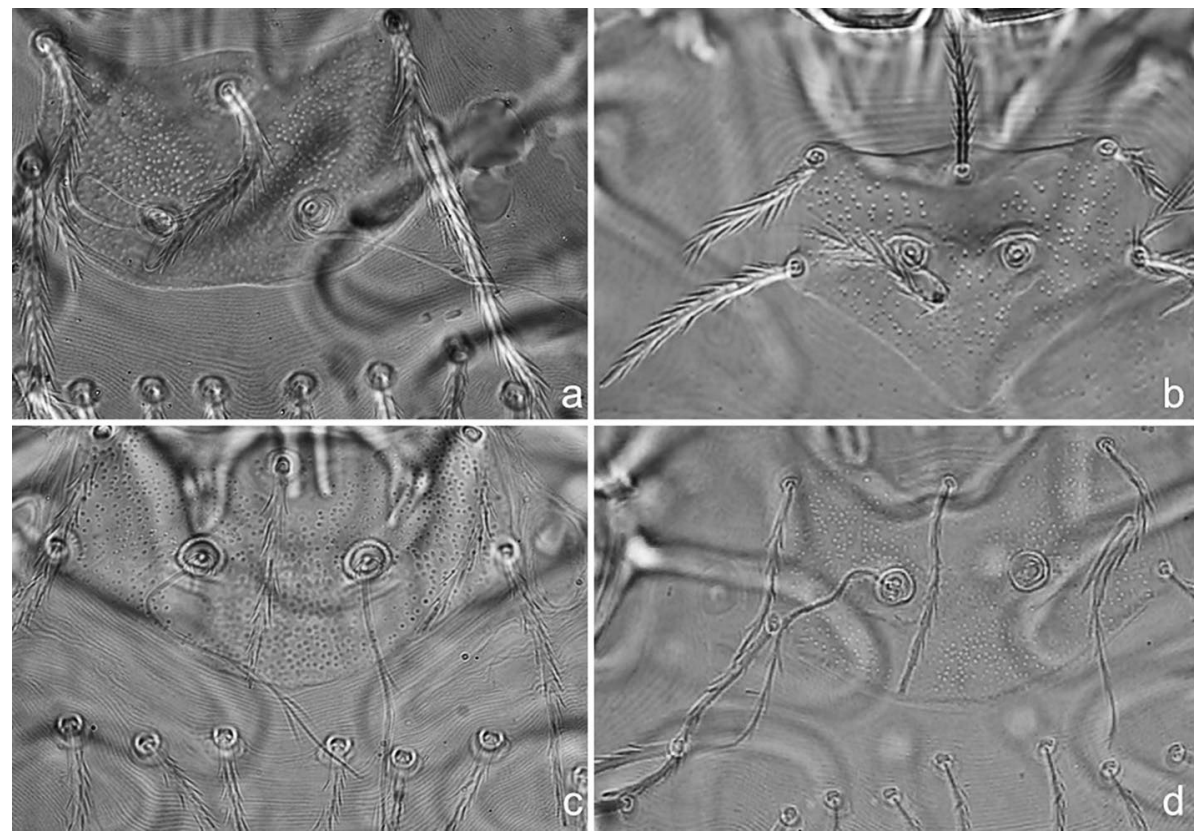

Fig. 2 Scutum of co-parasitizing species (larvae): a Hirsutiella zachvatkini, b Miyatrombicula muris, c Neotrombicula inopinata, $\mathbf{d}$ N. vulgaris (not to scale)

New Guinea, Goff (1979) reported 34.8\% cases of co-parasitism at the generic level and $46 \%$ at the specific level for trombiculids associated with Rattus ruber in disturbed areas. The respective values calculated for chiggers associated with Rattus niobe in undisturbed habitats were 0.6 and $12.5 \%$. The latter trend, considering the sample size, was slightly reflected also in our study, with the $100 \%$ incidence of co-invasions in the highly humanaffected collection site in Murowana Goślina. The high incidence of co-invasions (up to 46\%) in Papua New Guinea (Goff 1979), may be related to the much higher diversity and abundance of chigger species in the tropical compared to the temperate zone. As many as 114 nominal species of chiggers were reported from New Guinea (primarily from Papua New Guinea) (Goff 1982), whereas only 19 nominal species were recorded in Poland (Moniuszko and Mąkol 2014; Mąkol and Korniluk 2017).

For the majority of the recorded cases of parasitism, involving different host and parasite species, we could observe larvae to aggregate around the ear area. Only in the case of $N$. inopinata larvae were found also within the genital area. The latter observation, however, coincided with a relatively high level of infestation (Table 1). It cannot be excluded that larvae of particular species display a tendency to occupy alternative sites on the host's body at high levels of infestation in order to avoid competition with co-invading species. This may explain the differences in feeding sites observed in Neotrombicula sympatrica Stekolnikov in summer versus autumn, but also the reduced preferences for attachment sites observed in $H$. zachvatkini at maximum level of infestation in winter (Kharadov and Chirov 2007; Moniuszko and Mąkol 2016). Nonetheless, the observed parasitopes are among those listed by Goff (1979) and Kharadov and Chirov (2007). According to Goff (1979) the topic preferences of chiggers may be genusdependent. Traub and Wisseman (1968) claimed that topic preferences of larvae were 
host species-dependent. Barnard et al. (2015) pointed out that different chigger species displayed similar, non-random preferences for attachment to certain areas on the host's body and the knowledge of spatial segregation of parasites on host, translated into particular assemblage of parasites (sub-infra-community), was largely neglected. The tendency to form multiple individuals and species clusters by larvae may be targeted at reduction of moisture loss, and thus underlines the role of microclimatic conditions for the survival of larvae (Traub and Wisseman 1974; Barnard et al. 2015).

The relatively high proportion of hitherto observed co-invasions points to the need of separate identification of each individual parasite. Especially at high level of infestation, the selective identification of larvae may lead to false conclusions. The higher proportion of co-invasions reported for trombiculid mites (8.6\% in our study) compared to arthropodassociated terrestrial parasitengones may result from several factors. In case of chiggers, co-invasion may be facilitated by the constitution of the host body, physiological condition and availability of the hosts throughout the year, but also the potentially lower selectivity towards hosts in favour of habitat selectivity. According to Wohltmann (2000) parasitizing vertebrates, contrary to arthropod-associated taxa, reduced the selection pressures and made it possible for several species to exploit the same host synchronously. Xing-Yuan et al. (2007) revealed a positive correlation of both abundance and species richness of chigger mites versus the body weight of the host in Apodemus chevrieri (Milne-Edwards). For some trombiculids, for example H. zachvatkini, a prolonged contact with the host was described, extending beyond the parasitic phase; it also favours co-parasitic events (Moniuszko and Mąkol 2016). The fact that widely distributed chiggers usually exploit more hosts (Wrenn and Loomis 1984) should also be considered in the context of possible, increased numbers of co-invasion.

The genetic distance between the six compared sequences from representatives of possibly five genera varied between 21.1 and $41.3 \%$. Molecular intraspecific variation of trombiculid species is poorly known. Three COI sequences for Neotrombicula microti (Ewing) deposited in NCBI databases (Young et al. 2012) indicate that the intraspecific distance of this species is $0-3 \%$, whereas the distance to another member of the same genus (Neotrombicula sp.) is $10-11.5 \%$. Hebert et al. $(2003,2004)$ defined the 'barcoding gap' as the existence of average interspecific distance at least $10 \times$ greater than the average intraspecific genetic distance, but there are no guidelines for determination of higher systematic ranks (genera and families). Among other invertebrates K2P distances at COI within species, within genus and within family varied within $0.17-0.36,5.8-9.1$ and $10-12.5$, respectively, for Lepidoptera (Hebert et al. 2003); within 0-7.6, 19-27 and 22.3-35.6 for Thysanoptera (Iftikhar et al. 2016); they were 0-7.7, up to 24.8 and up to 35.8 for Hemiptera (Park et al. 2011), up to 26.2, up to 37 and even up to 40.3 for molluscs (Sun et al. 2016). It is clear that all the analysed trombiculid specimens represent distinct species, whether they all belong to separate genera requires further analysis. Specimens assigned in our study to spp. A and B may actually represent one of the seven rodent-associated trombiculid species hitherto recorded from Poland (Moniuszko and Mąkol 2014) and known exclusively from larvae.

Despite all the hitherto records, the actual prevalence of co-parasitism, its ecological background and topic segregation of parasites still remain largely obscure due to various factors. Of those, difficulties in proper processing and time-consuming counts of the mites from particular parts of the host body as pointed by Barnard et al. (2015) play a crucial role, but also the unrecognized intra- and interspecific variation of parasites, the selective sampling of mites at high intensity of infestation as well as the side-effect conclusions drawn by the way of projects focusing either on host or on particular species of parasite. 
Acknowledgements We thank Grzegorz Zaleśny for his help in molecular analysis and Paula Zajkowska and Jan Cichocki for providing material from the Sanocko-Turczańskie Mts. and Tatra Mts. Two anonymous reviewers provided constructive comments on the manuscript. The work of HM was supported by the National Science Centre of Poland (Decision No. DEC-2012/07/N/NZ8/02354).

Open Access This article is distributed under the terms of the Creative Commons Attribution 4.0 International License (http://creativecommons.org/licenses/by/4.0/), which permits unrestricted use, distribution, and reproduction in any medium, provided you give appropriate credit to the original author(s) and the source, provide a link to the Creative Commons license, and indicate if changes were made.

\section{References}

Barnard K, Krasnov RB, Goff ML, Matthee S (2015) Infracommunity dynamics of chiggers (Trombiculidae) parasitic on a rodent. Parasitology 142:1605-1611

Dabert M, Witaliński W, Kaźmierski A, Olszanowski Z, Dabert J (2010) Molecular phylogeny of acariform mites (Acari, Arachnida): strong conflict between phylogenetic signal and long-branch attraction artifacts. Mol Phylogenet Evol 56:222-241

Daniel M (1961) The bionomics and developmental cycle of some chiggers (Acariformes, Trombiculidae) in the Slovak Carpathians. Cesk Parasitol 8:31-118

Efford IE (1963) The parasitic ecology of some watermites. J Anim Ecol 32:141-156

Felska M, Wohltmann A, Mąkol J (2018) A synopsis of host-parasite associations between Trombidioidea (Trombidiformes: Prostigmata, Parasitengona) and arthropod hosts. Syst Appl Acarol 23:1375-1479

Goff ML (1979) Host exploitation by chiggers (Acari: Trombiculidae) infesting Papua New Guinea land mammals. Pac Insects 20:321-353

Goff ML (1982) New Guinea chiggers (Acari: Trombiculidae). Monographiae Biologicae 42:545-555

Haitlinger R (1979) Pasożyty zewnętrzne nietoperzy Dolnego Śląska. V. Trombidiformes, Sarcoptiformes (Acarina). Wiad Parazytol 25:105-117 (in Polish)

Hebert PDN, Cywińska A, Ball SL, deWaard JR (2003) Biological identifications through DNA barcodes. Proc R Soc Lond B Biol Sci 270:313-321

Hebert PDN, Stoeckle MY, Zemlak TS, Francis CM (2004) Identification of birds through DNA barcodes. PLoS Biol 2:e312

Iftikhar R, Ashfaq M, Rasool A, Hebert PDN (2016) DNA barcode analysis of thrips (Thysanoptera) diversity in Pakistan reveals cryptic species complexes. PLoS ONE 11:e0146014

Key KHL (1994) Host relations and distribution of the Australian species of Eutrombidium (Acarina, Microtrombidiidae) a parasite of grasshoppers. Aust J Zool 42:363-370

Kharadov AV, Chirov PA (2007) Localisation of Neotrombicula sympatrica (Acariformes: Trombiculidae) on small rodents of Kyrgyzstan. Folia Entomol Hung 68:181-194

Kimura M (1980) A simple method for estimating evolutionary rate of base substitutions through comparative studies of nucleotide sequences. J Mol Evol 16:111-120

Kudryashova NI (1998) Chigger mites (Acariformes, Trombiculidae) of East Palaearctics. KMK Scientific Press, Moscow (in Russian)

Kumar S, Stecher G, Tamura K (2016) Molecular evolutionary genetic analysis version 7.0 for bigger dataset. Mol Biol Evol 33:1870-1874

Mąkol J, Korniluk M (2017) Blankaartia acuscutellaris (Walch, 1922) (Actinotrichida: Trombiculidae) collected from the great snipe Gallinago media (Latham, 1787) (Charadriformes: Scolopacidae) in Poland - new host and country record for chigger mite genus and species. Acarologia 57:555-562

Mohr C (1956) Comparative infestation by ectoparasites of two native rats of Sansapor, New Guinea. Am Midl Nat 55:382-392

Moniuszko H, Mąkol J (2014) Chigger mites (Actinotrichida: Parasitengona, Trombiculidae) of Poland. An updated distribution and hosts. Ann Parasitol 60:103-117

Moniuszko H, Mąkol J (2016) Host-parasite association in trombiculid mites (Actinotrichida: Trombiculidae) of temperate zone-the case of Hirsutiella zachvatkini (Schluger, 1948); are we dealing with prolonged contact with the host? Parasit Vectors 9:61

Moniuszko H, Zaleśny G, Mąkol J (2015) Host-associated differences in morphometric traits of parasitic larvae Hirsutiella zachvatkini (Actinotrichida: Trombiculidae). Exp Appl Acarol 67:123-133

Moniuszko H, Shatrov AB, Mąkol J (2017) Description of active post-larval forms of Neotrombicula vulgaris (Schluger, 1955) (Prostigmata: Trombiculidae), with notes on biology and ecology of the species. Ann Zool 67:243-251 
Park D-S, Foottit R, Maw E, Hebert PDN (2011) Barcoding bugs: DNA-based identification of the true bugs (Insecta: Hemiptera: Heteroptera). PLoS ONE 6:e18749

Shatrov AB, Kudryashova NI (2008) Taxonomic ranking of major trombiculid subtaxa with remarks on the evolution of host-parasite relationships (Acariformes: Parasitengona: Trombiculidae). Ann Zool 58:279-287

Southcott RV (1986) Australian larvae of the genus Trombella (Acarina: Trombidioidea). Aust J Zool 34:611-646

Stahr C (2014) Pheromonphysiologie und ektoparasitische Parasitengona (Acari, Prostigmata) bei Schistocerca piceifrons (Orthoptera, Acrididae) als mögliche Grundlagen zur integrierten Schädlingsbekämpfung. PhD thesis, University of Halle, Germany

Sun S, Li Q, Kong L, Yu H, Zheng X, Yu R, Dai L, Sun Y, Chen J, Liu J, Ni L, Feng Y, Yu Z, Zou S, Lin J (2016) DNA barcoding reveal patterns of species diversity among northwestern Pacific molluscs. Sci Rep 6:33367

Traub R, Wisseman CL Jr (1968) Ecological considerations in scrub typhus. 2. Vector species. Bull WHO 39:219-230

Traub R, Wisseman CL Jr (1974) The ecology of chigger-borne rickettsiosis (scrub typhus). J Med Entomol 11:237-303

Vercammen-Grandjean PH (1963) Contribution a l'étude de la faune d'Afghanistan 77.-Trombiculidae de chiroptères. Acarologia 5:582-615

Vercammen-Grandjean PH (1975) Some larvae of Trombiculidae of the Ethiopian region (Acari). Rev Zool Bot Afr 89:397-439

Wohltmann A (2000) The evolution of life histories in Parasitengona (Acari: Prostigmata). Acarologia 41:145-204

Wohltmann A (2001) Closely related species of Parasitengonae (Acari: Prostigmata) inhabiting the same area: features facilitating coexistence. In: Halliday RB, DE Walter, Proctor HC, Norton RA, Colloff MJ (eds) Proceedings of the 10th international congress of acarology. CSIRO Publishing, Melbourne, pp $121-135$

Wrenn WJ, Loomis RB (1984) Host selectivity in the genus Eutrombicula (Acari: Trombiculidae). In: Griffiths DA, Bowman CE (eds) Acarology VI, vol 1. Ellis-Horwood Ltd., Chichester, pp 160-165

Xing-Yuan M, Xian-Guo G, Wen-Ge D, Ai-Qin N, Ti-Jun Q, Dian W (2007) Ectoparasites of Chevrier's field mouse, Apodemus chevrieri, in a focus of plague in southwest China. Med Vet Entomol 21:297-300

Young MR, Behan-Pelletier VM, Hebert PDN (2012) Revealing the hyperdiverse mite fauna of subarctic Canada through DNA barcoding. PLoS ONE 7:e48755 